\title{
PROJECTIONS AND THE KADISON-SINGER PROBLEM
}

\author{
Pete Casazza, Dan Edidin, Deepti Kalra and Vern I. Paulsen
}

Abstract. We prove some new equivalences of the paving conjecture and obtain some estimates on the paving constants. In addition we give a new family of counterexamples to one of the Akemann-Anderson conjectures.

Mathematics subject classification (2000): 46L15, 47L25.

Key words and phrases: Frame, paving, Kadison-Singer.

\section{REFERENCES}

[1] C. A. Akemann And J. Anderson, Lyapunov theorems for Operator Algebras, Mem. Amer. Math. Soc. 94458 (1991).

[2] J. ANDERSON, Extensions, restrictions and representations of states on $C^{*}$-algebras, Trans. Amer. Math. Soc. 249 (1979), 303-329.

[3] J. ANDERSON, Extreme points in sets of positive linear maps on B(H), J. Func. Anal. 31 (1979), 195-217.

[4] J. ANDERSON, A conjecture concerning pure states of $B(H)$ and a related theorem, in Proceedings, Vth International Conference Operator Algebras, Timisoara and Herculane, Romania, Pitman, New York/London, 1984.

[5] K. BERMAN, H. HALPERN, V. KAFTAL AND G. WeISS, Matrix norm inequalities and the relative Dixmier property, Integ. Eqns. and Operator Theory 11 (1988) 28-48.

[6] K. Berman, H. Halpern, V. Kaftal and G. Weiss, Some $C_{4}$ and $C_{6}$ Norm Inequalities Related to the Paving Problem, Proceedings of Symposia in Pure Mathematics, 51 (1990), 29-41.

[7] B. G. BoDmann AND V. I. PAULSEN, Frames, graphs and erasures, Lin. Alg. and Appl. 404 (2005), 118-146.

[8] J. Bourgain AND L. TZAFRIRI, On a problem of Kadison and Singer, J. Reine Angew. Math. 420 (1991), $1-43$.

[9] M. BOWNIK AND D. SPEEGLE, The Feichtinger conjecture for wavelet frames, Gabor frames and frames of translates, Preprint.

[10] P. G. Casazza, M. Fickus, J. C. Tremain and E. Weber, The Kadison-Singer Problem in Mathematics and Engineering: A Detailed Account, Operator Theory, Operator Algebras and Applications, Proceedings of the 25th GPOTS Symposium (2005), D. Han, P. E. T. Jorgensen and D. R. Larson Eds., Contemporary Math 414 (2006) 299-356.

[11] P. G. CAsazZA, G. KutYNioK And D. Speegle, A redundant version of the Rado-Horn theorem, Preprint.

[12] P. G. CasazZa And J. C. Tremain, The Kadison-Singer Problem in Mathematics and Engineering, Proceedings of the National Academy of Sciences, 103 No. 7 (2006) 2032-2039.

[13] O. Christensen, An introduction to frames and Riesz bases, Birkhauser, Boston, 2003.

[14] H. HALPERN, V. KAFTAL AND G. Weiss, Matrix pavings in $B(\mathbb{H})$, Proc. $10^{\text {th }}$ International conference on operator theory, Increst 1985; Advances and Applications 24 (1987) 201-214.

[15] H. HalPern, V. Kaftal AND G. Weiss, The Relative Dixmier Property in Discrete Crossed Products, J. Functional Anal. 68 (1986)

[16] H. HalPern, V. Kaftal and G. Weiss, Matrix Pavings and Laurent Operators, J. Operator Thy. 16 (1986) 121-140.

[17] R. B. Holmes AND V. I. PAulsen, Optimal frames for erasures, Lin. Alg. and Appl. 377 (2004), 31-51.

[18] R. KAdison AND I. Singer, Extensions of pure states, Amer. J. Math. 81 (1959), 547-564. 
[19] D. KalRA, Cyclic Equiangular Frames, Lin. Alg. and Appl., to appear.

[20] V. I. PAUlSen, Equivariant Maps and Bimodule Projections, J. Func. Anal. 240 (2006), 495-507.

[21] N. WEAVER, A counterexample to a conjecture of Akemann and Anderson, Bull. London Math. Soc. 34 (2002), 1-7. 